\title{
Research Paper: Comparison of the Kyphosis Angle, Position, Muscles Strength, and Range of Motion of Shoulders in Volleyball Players With and Without Shoulder Impingement Syndrome
}

\author{
Seyed Kazem Mousavi Sadati ${ }^{*}$ iD , Hasan Yazdani ${ }^{1}$ (D) \\ 1. Department of Physical Education \& Sport Sciences, Faculty of Humanities, East Tehran Branch, Islamic Azad University, Tehran, Iran
}

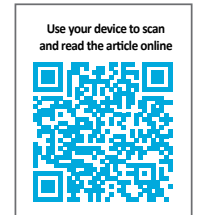

Citation Mousavi Sadati SK, Yazdani H. Comparison of the Kyphosis Angle, Position, Muscles Strength, and Range of Motion of Shoulders in Volleyball Players With and Without Shoulder Impingement Syndrome. 2020; 9(1):79-88. http://dx.doi. org/10.32598/ptj.10.2.436.1

dol $:$ http://dx.doi.org/10.32598/ptj.10.2.436.1

\section{Keywords:}

Kyphosis angle, Shoulder position, Volleyball player, Impingement syndrome

\begin{abstract}
A B S T R A C T
Purpose: This case-control study aimed at comparing the kyphosis angle, position of the shoulder, the strength of rotator cuff muscles, and the range of shoulder motions in volleyball players with and without impingement syndrome.

Methods: The participants were 22 male professional volleyball players with at least 5 years of training experience. Eleven volleyball players with impingement syndrome and eleven without impingement syndrome were selected from accessible gyms by simple non-probabilistic sampling. The research tools were a flexible ruler, a measuring tape, a goniometer, a pull-up bar, a dynamometer, and tests to measure the distance between spinal midline and the shoulder, kyphosis angle, flexibility, range of motion, and isometric strength of the shoulder girdle muscles in abduction, adduction, flexion, extension, horizontal adduction, and horizontal abduction. Data were analyzed using SPSS V. 19 software and the Shapiro-Wilk test and independent t-test.
\end{abstract}

Results: There was a significant difference between the two groups in terms of kyphosis angle, the distance between spinal midline and the shoulder, range of motion of the glenohumeral joint in abduction, and isometric strength of the shoulder girdle muscles in abduction, flexion, and extension $(\mathrm{P}<0.01)$. However, no significant difference was observed between the two groups in terms of flexibility of the shoulder when lying on the abdomen with arms stretched out in front, endurance in the strength of the shoulder girdle muscles, and isometric strength of the shoulder girdle muscles in adduction, horizontal adduction, and horizontal abduction $(\mathrm{P}>0.05)$.

Conclusion: The results of this study showed that angle of kyphosis, scapula distance to spine, range of motion of the shoulder, factor profile of a range of motion, and isometric muscle strength of shoulder girdle altered in people with shoulder impingement syndrome, and dysfunctions in these factors may result in shoulder impingement syndrome and athlete performance inefficiency.

\footnotetext{
* Corresponding Author:

Seyed Kazem Mousavi Sadati, PhD.

Address: Department of Physical Education \& Sport Sciences, Faculty of Humanities, East Tehran branch, Islamic Azad University, Tehran, Iran Phone: +98 (21) 33587402

E-mail:drmousavisadati@gmail.com
} 


\section{Highlights}

- Changing the normal position of the scapula causes a biomechanical disorder in the shoulder joint;

- The abnormal posture of the scapula will presumably diminish the subacromial space and leads to a shoulder injury;

\section{Plain Language Summary}

The purpose of this study was to compare the kyphosis angle, position of the shoulder, the strength of rotator cuff muscles, and the range of shoulder motions in two groups of volleyball players with and without impingement syndrome. The results of this study showed that in people with impingement syndrome, the kyphosis angle increased, the distance of the scapula from the spine at the affected side increased, the range of shoulder extension decreased, and the isometric strength of the shoulder involved in the abduction, flexion, and extension reduced.

\section{Introduction}

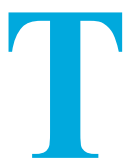

he shoulder is vulnerable to multiple injuries in sports, such as tennis and volleyball, or throwing or overhead sports, because it faces considerable load and force while spiking and attacking. The risk of such injuries seems to increases with age [1]. To progress, the player must follow longterm training programs. Each sport entails its own requirements that cause physical and physiological adaptability in the player's body. Most of these adaptations are positive and help to improve cardiovascular endurance, enhance muscular strength, and diminish body fat, but sometimes this is a negative postural adaptation and affects the player's physical appearance and causes postural abnormalities $[2,3]$.

Changes in scapular position, scapulohumeral rhythm, weak shoulder posture, and muscular imbalance around the shoulder (e.g., imbalance of the anterior and posterior shoulder muscles) seem to be leading factors for shoulder anomalies and chronic pain syndromes [4]. The correct position of the scapula on the chest is highly important because changing its normal position causes a biomechanical disorder in the shoulder joint. The weakness of the scapula to maintain its position and connect with the shoulder joint and associated muscles leads to injury or abnormal posture. Such abnormal posture of the scapula will presumably diminish the subacromial space and leads to a change in the order of movement of the upper limbs, and ultimately motion disorders [5].

Shoulder injuries are amongst the prevalent difficulties in different people. Of all the shoulder injuries, impingement syndrome is more widespread and regarded as the main cause of pain and restricted motion in the shoulder area. This syndrome is more common in people younger than 60 years and is ordinarily after exercise or other overhead activities involving arms [6]. Shoulder motion is a crucial element of natural shoulder movements, especially when stretching the hands upward.

This factor is employed by researchers and therapists to assess and treat shoulder disorders. During the lift of the upper limb, the scapula rotates upward and posteriorly to the glenoid to expand the subacromial space and provide more area for other organs. Otherwise, the impingement syndrome will happen and appears with pain when the player moves his hands [7]. The annual prevalence of shoulder pain is $0.9 \%-2.5 \%$ depending on age. Impingement syndrome is the most common cause of shoulder pain that accounts for $48 \%$ of specular disorders [8]. This normally happens in players during overhead movements [9]. The kinematic shoulder shifts or scapular dyskinesis (depression, anterior tilt, and medial rotation of the scapula) can lead to impingement syndrome by decreasing the subacromial space. Supraspinatus is the foremost rotator cuff muscle that is highly vulnerable to disorder [10].

Thoracic kyphosis is one of the main spinal curves. An irregular increase in the thoracic curves (kyphosis) is a prevalent postural disorder and a leading factor affecting the upper quarter of the body resulting in shoulder pain [11]. Functional or postural kyphosis can result from wrong postures and irregular exercises and sports Under this circumstance, the pectoralis major and minor muscles and the stratus anterior are tightened and shortened, whilst erector spine, rhomboids, and trapezius are stretched and weakened [12].

The function of the scapula is vital for regular movements and coordinating shoulder girdle so that variations in the normal position of the scapula and the function of 
its supporting muscles can lead to the development of abnormal shoulder girdle biomechanics [13]. Scapular dislocation influences the function and energy generation of the shoulder girdle, especially the muscles supporting the scapula. Accordingly, repetitive movements, such as abduction and lateral rotation accompanied by extension and medial rotation, as well as spiking under abduction increases the impingement force [14].

Smith et al. (2002) investigated the impact of scapula circumference on the isometric strength of the shoulder elevation and found that the scapula in the distal or proximal posture significantly reduces the isometric strength of the shoulder [15]. Trip et al. (2007) investigated the effect of fatigue on the sensation of the upper limb posture and reported that fatigue can negatively affect the sensation of the posture of glenohumeral and scapulothoracic joints in different movements and leads to impingement syndrome in throwing athletes [16]. Similar results were also reported by Seyedjafari et al. (2015) [17].

Despite limited research on the relationship between kyphosis angle, posture, muscular strength, and range of motion with impingement syndrome, information to launch corrective and therapeutic protocols is insufficient [18]. Also, no study has been conducted on volleyball players in this regard. Accordingly, this study aimed at comparing the kyphosis angle, position of the scapula, the strength of rotator cuff muscles, and the range of scapular motions in volleyball players with and without impingement syndrome.

\section{Materials and Methods}

In this case-control study, professional male volleyball players of the North Khorasan, Iran with at least 5 years of experience in volleyball training and the experience of attending the premier league or national competitions for two years were screened for impingement syndrome upon signing the consent form. All volleyball players with impingement syndrome $(n=11)$ were selected with the approval of an orthopedist. After determining the range of age (18-28), height (175-195), and weight (75-95) of the participants, 11 players with impingement syndrome were included in the test group. Also, 11 volleyball players without impingement syndrome matched for gender and age, height, and weight were included in the control group. Finally, the distance between spinal midline and the scapula, kyphosis angle, flexibility, range of motion, strength endurance, and isometric strength of the shoulder girdle muscles in abduction, adduction, flexion, extension, horizontal adduction, and horizontal abduction were compared between the two groups.
Inclusion criteria were having impingement syndrome (or having no impingement syndrome for the control group) and having at least 5 years of experience in volleyball training and experience of attending the premier league or national competitions for two years. Exclusion criteria were a history of cardiovascular disease, neurological disease, dislocation, fracture, joint disease of the shoulder girdle, congenital anomalies, and limited shoulder mobility. Research tools were: 1. a hand dynamometer to measure the maximum isometric strength of the shoulder girdle muscles in abduction, adduction, flexion, extension, horizontal adduction, and horizontal abduction; 2. A flexible ruler to measure kyphosis angle; 3. a measuring tape to measure shoulder position; and 4. a goniometer to measure the range of shoulder motion, and a pull-up bar to measure endurance in the strength of rotator cuff muscles. Also, tests were randomly selected for each participant to avoid the impact of fatigue on results.

The measurement of kyphosis angle, position, muscular strength, and range of motion of the shoulder

\section{Kyphosis measurement}

The player was first asked to bend his head and neck forward so that the $\mathrm{C} 7$ ( $7^{\text {th }}$ cervical vertebra) was fully exposed. The spinous processes of the $\mathrm{C} 7$ vertebra, which is the largest cervical vertebra, are marked. Then, the index finger was put on the twelfth rib and extended. The T12 vertebra was determined and marked with the thumb finger. The player was asked to bend forward to ensure the correctness of the measurement. Most of the motions take place in the T12 vertebra. The flexible ruler was placed on the back arch between the two points (Figure 1), and the ruler's appearance was schematically drawn on the paper without any change. The first

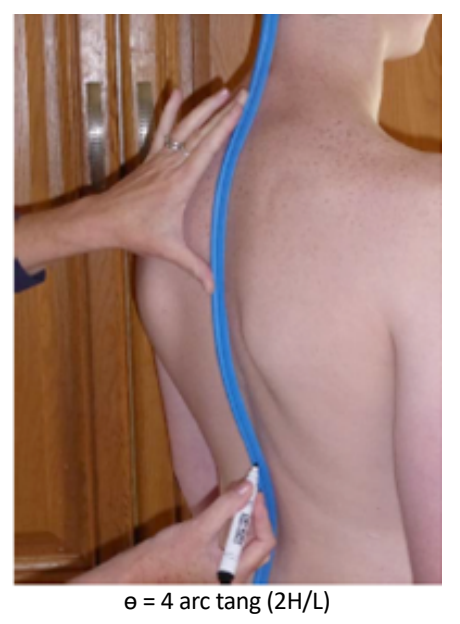

PHYSICAL TREA TMENTS

Figure 1. Flexible ruler 

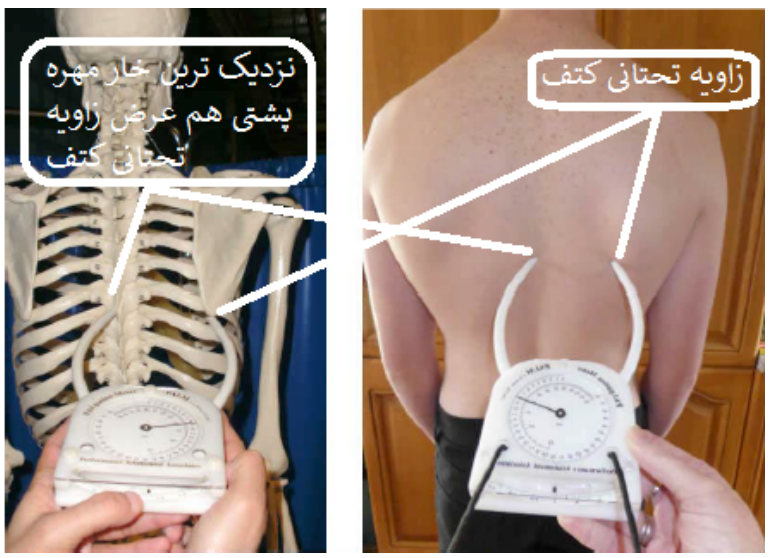

Figure 2. Measuring the scapula position

PHYSICAL TREA $\mid$ MENTS

vertebra was connected to the twelfth vertebra and the value obtained was represented as L. The deepest curve point was connected to the $\mathrm{L}$ on the paper to calculate the value of $\mathrm{H}$. Kyphosis angle was finally calculated by the following formula [19]:

\section{Measuring the scapula position}

The player was asked to stand while turning his back to the test operator and with arms that were at a neutral position next to the body. Under this position, the inner edge of the lower angle of the scapula was marked. Then, the spinous process of the closest vertebra corresponding to the lower angle of the scapula was detected and marked (Figure 2). In the next step, the distance between these two points was measured [19].

The maximum isometric force of lateral and medial rotations

The player was asked to lie on the abdomen with his/her head turning toward the tester. The shoulder lies on the bed under 90 degrees at abduction, the elbow was fully on the bed and the forearm hangs from the edge of the bed vertically. A folded towel was placed under the arm. The dynamometer was placed close to the steroid appendix of the radius bone and at the dorsal surface of the wrist to measure the isometric force of the lateral rotation. The dynamometer was placed close to the steroid appendix of the radius bone and at the palm of the wrist to measure medial rotation. The player resists the lateral rotation force. In this situation, the isometric force exerted by the player was recorded from the digital screen $[20,21]$.

Maximum isometric force at abduction and adduction

The player seated on a chair holding the shoulder under 75 degrees at abduction at the frontal plate to measure the abduction force of the shoulder. The player's shoul-

der was fixed by someone else, and the tester kept the device in the outer-lower and outer-upper part of the arm asking the player to apply maximum force to the device in the direction of adduction and abduction motions [22].

The maximum isometric force of flexion and extension motions

The player lay on the bed in a supine position while hands are hanging from the bed. The device was supported on the anterior-lower level of the forearm. The player was asked to force upwards with a straight elbow. To measure the extension strength, the player was asked to lie on the abdomen while hands are hanging from the bed. Then, the device was maintained on the posteriorlower surface of the arm and the player was asked to force upwards [22].

\section{The maximum isometric force of horizontal ab- duction and adduction}

To measure the strength of the horizontal abduction, the player was asked to lie in a supine position, with shoulder and elbow bent at 90 degrees. The tester held the device in the outer-lower part of the arm and asked the player to apply force to the outer and lower direction. To measure the strength of the horizontal adduction, the tester held the device in the inner-lower part of the arm asking the player to apply the force to the outer and lower direction [22].

\section{Endurance in the strength of shoulder girdle muscles}

This test requires a timer and a pull-up bar. The pull-up bar was fixed at a height, where the tallest player does not touch the ground after hanging. To perform the test, the player was situated on top of the bar with the help of another person so that his chin did not touch the bar. The elbows remain bent and the palms of the hands toward the 
ground. The player will remain in this state as long as he can. The duration a player can keep himself in the correct position (i.e. holding chin above the bar with bent elbows) is an index for scoring. As soon as the player starts this position, the timer starts to measure the duration. Contrarily, the timer stops as soon as the chin touch the bar or comes bellow the bar, or when the elbows open [22].

\section{Shoulder flexibility when lying on the abdomen}

The player lay on the abdomen and held the ruler with outstretched arms (as same as the shoulder width). The tester put the zero number in the middle of the ruler on the ground. The player tried to stretch his hands up from the shoulder joint while his chin was not detached from the ground and his head was fully on the ground. The tester measured the highest shoulder height by keeping the zero number on the ground. The test repeated twice. The highest score obtained after two correct repetitions will be the score [23].

\section{The flexibility of bringing hands on the back}

The player lifted his left hand over his head and then held it behind his head by bending his elbow and staying under this state. Then, he pulled his right hand downward and tried to bring the hands together by bending elbows. The distance between the two hands was measured with a ruler. The test was repeated with opposite shoulders [23]. Data were analyzed using SPSS ... software and the Shapiro-Wilk test and independent t-test.

\section{Results}

The demographic characteristics of the two groups are summarized in Table 1. The results showed no significant difference between the two groups in demographic characteristics $(\mathrm{P}>0.05)$.

According to the results of Table 2 (comparing cases with and without impingement syndrome), there was a

Table 1. Demographic characteristics of the two groups (with and without impingement syndrome)

\begin{tabular}{cccc}
\hline & & \multicolumn{2}{c}{ Mean \pm SD } \\
\cline { 2 - 4 } & Height $(\mathbf{c m})$ & Weight (kg) & Age $(\mathbf{v})$ \\
\hline With impingement syndrome $(n=11)$ & $187.73 \pm 2.46$ & $81.55 \pm 3.56$ & $23.36 \pm 3.03$ \\
Without impingement syndrome & $186.91 \pm 3.08$ & $82.64 \pm 2.54$ & $22.36 \pm 2.24$ \\
P value & 0.937 & 0.563 & 0.693 \\
\hline
\end{tabular}

PHYSICAL TREA $\ M E N T S$

Table 2. Comparison of the test variables between the test and control groups

\begin{tabular}{|c|c|c|c|c|}
\hline \multirow{3}{*}{ Variables } & \multicolumn{2}{|c|}{ Mean \pm SD } & \multirow{3}{*}{$\mathbf{t}$} & \multirow{3}{*}{$\mathbf{P}$} \\
\hline & \multicolumn{2}{|c|}{ Groups } & & \\
\hline & Test & Control & & \\
\hline Kyphosis angle (degree) & $49.75 \pm 4.93$ & $40.27 \pm 3.37$ & 5.262 & $0.001 *$ \\
\hline Distance between spinal midline and the shoulder $(\mathrm{cm})$ & $13.15 \pm 0.202$ & $12.43 \pm 0.261$ & 3.995 & $0.001 *$ \\
\hline Range of motion of the shoulder in extension (degree) & $52.91 \pm 5.06$ & $57.09 \pm 5.52$ & 1.850 & 0.079 \\
\hline Range of motion of the shoulder in flexion (degree) & $197.18 \pm 30.808$ & $189 \pm 4.690$ & 0.297 & 0.797 \\
\hline Range of motion of the shoulder in abduction (degree) & $115.36 \pm 5.240$ & $183.73 \pm 5.605$ & 3.978 & $0.001 *$ \\
\hline Shoulder flexibility in prone position (cm) & $26.34 \pm 2.64$ & $28.09 \pm 3.02$ & 1.088 & 0.300 \\
\hline Shoulder flexibility when bringing hands on the back $(\mathrm{cm})$ & $2.09 \pm 0.701$ & $1.55 \pm 0.522$ & 2.070 & 0.052 \\
\hline Endurance of rotator cuff muscles (s) & $22.40 \pm 2.860$ & $23.87 \pm 1.449$ & 1.524 & 0.143 \\
\hline Isometric strength of shoulder girdle muscles in adduction (kg) & $26.59 \pm 1.59$ & $28.73 \pm 2.96$ & 2.102 & 0.052 \\
\hline Isometric strength of shoulder girdle muscles in abduction (kg) & $25.54 \pm 0.98$ & $29.91 \pm 1.90$ & 6.77 & $0.001^{*}$ \\
\hline Isometric strength of shoulder girdle muscles in horizontal adduction (kg) & $25.31 \pm 2.40$ & $25.36 \pm 4.63$ & 0.029 & 0.977 \\
\hline Isometric strength of shoulder girdle muscles in horizontal abduction (kg) & $25.77 \pm 1.58$ & $27.10 \pm 2.00$ & 1.72 & 0.101 \\
\hline Isometric strength of shoulder girdle muscles in flexion (kg) & $27.72 \pm 1.31$ & $29.72 \pm 1.79$ & 2.98 & $0.007^{*}$ \\
\hline Isometric strength of shoulder girdle muscles in extension (kg) & $27.81 \pm 1.69$ & $30.36 \pm 1.28$ & 3.97 & $0.001^{*}$ \\
\hline
\end{tabular}

* Significant at 0.01 . 
significant difference between the two groups in terms of kyphosis angle, the distance between spinal midline and the scapula, range of motion of the glenohumeral joint in abduction, and isometric strength of the shoulder girdle muscles in abduction, flexion, and extension $(\mathrm{P}<0.01)$. However, no significant difference was observed between the two groups in terms of flexibility of the shoulder when lying on the abdomen with arms stretched out in front, endurance in the strength of the shoulder girdle muscles, and isometric strength of the shoulder girdle muscles in adduction, horizontal adduction and horizontal abduction $(\mathrm{P}>0.05)$.

\section{Discussion}

Based on the obtained results, the kyphosis angle and the distance from the scapula to the shoulder of volleyball players with impingement syndrome were significantly more than volleyball players without the syndrome. Such difference in kyphosis angle can be due to the shortness of the pectoralis major and minor muscles and the stratus anterior and large posterior, as well as weakness of the erector spine, rhomboids, and trapezius, congenital factors, etc. These findings show that muscles supporting the scapula of the volleyball players with the syndrome lead inappropriate position of the scapula so that the scapula cannot efficiently control the rhythm of the shoulder.

According to the results, the protraction of the scapular bone from the spine increases with an increase in the curvature of the thoracic kyphosis. There is a significant positive relationship between the strength of the protector's muscle and dorsal kyphosis. Higher strength is associated with higher kyphosis. Also, lower tolerance of the shoulder retractor muscles (i.e., muscles behind the shoulder girdle) and the trunk extensor is associated with elevated kyphosis in the back. These findings are in constant with the results reported by Daneshmandi (2010) indicating a significant association between the degree of curvature of the thoracic kyphosis and the degree of scapular protraction [24]. Gary (2012) stated that the increase in thoracic kyphosis is linked to reduced physical function, increased neck pain, and shoulder conditions (e.g., subacromial syndrome) [25].

Briggs (2007) reported that excessive and repetitive overhead activities and abnormal shoulder changes in overhead activities are amongst the prevalent causes of shoulder pain and disability in athletes with overhead activities [26]. Lewis et al. (2005) researched the influence of strengthening the trunk extensor muscles in older women and found that increasing the strength of the back extensor muscles leads to a reduction in the thoracic angle [27]. Wang and Cochrane (2001) stated that dislocation of the scapula affects the performance and generation of the shoulder girdle muscle force, especially the scapular-supporting muscles so that repetitive movements, such as abduction and external rotation followed by extension and medial rotation in volleyball players, as well as spiking under maximum abduction increases the impingement force [14].

According to Mottram's theory (1997), muscle weakness causes atrophy and the increased length of the muscles between the scapula and the spine, resulting in the high distance between the scapula and the spine. Such scapular protraction disrupts the coordinated rhythm of the shoulder joint during different movements [28]. In general, differences in the type of test and body mass, age, height, and gender may be the reasons for the inconsistency of the results presented.

Based on our results, although the flexibility of the shoulder in the posterior position, bringing the arms from behind, and the range of motion of the shoulder joint in motion were lower in players with the syndrome, there was only a significant difference between the two groups in terms of the range of motion of the shoulder joint. This finding can be justified by the fact that the weakness of the supraspinatus muscle and the pressure of the supraspinatus tendon between the two bony surfaces of the subacromial joint and the end of the humerus at an angle of 90120 degrees cause significant limitations in the abduction in volleyball players with impingement syndrome. These results are consistent with the findings of Merula et al. (2010) reporting a decrease in the power of supraspinatus in overhead players with impingement syndrome [29].

According to the results, endurance in the strength of the shoulder muscles of volleyball players in the two groups did not vary significantly. Rajabi (2003) examined the relationship between shoulder bone position and shoulder girdle muscle endurance on healthy non-athletic boys. He used the pull-up bar and reported that increasing shoulder bone distance decreases endurance and performance of shoulder girdle muscles, and endurance of the shoulder girdle muscles of the scapular group was more for closedspecula players than the distal-scapula ones, which may be due to different experiences of the players [30].

The findings of this study revealed that there was no difference between the two groups in terms of shoulder girdle muscle strength in adduction, horizontal adduction, and horizontal abduction. However, the shoulder girdle muscle strength in players with the syndrome was significantly lower in abduction, flexion, and extension. Im- 
pingement syndrome and kinematic change of the scapula that happens due to scapular motion disorder can diminish inflammation in the subacromial space, causing inflammation in the elements in the subacromial space, of which supraspinatus tendon is the most important element [31].

In players with impingement syndrome, the subacromial space is reduced, which affects tissues, such as the subacromial bursa, the supraspinatus tendon, and the long head of the biceps, which are located in the subacromial space. However, the greatest damage is mainly on the tendon of the upper muscle, and tendinopathy of this muscle is prevalent [32]. According to Nodehi (2018), people with dyskinesia of the scapula show a significant decrease in the maximum isometric force of scaption movements (with lateral rotation), adduction with the lower rotation of the scapula, and adduction with the scapula depression, indicating weakness in the middle deltoid, supraspinatus, serratus anterior, middle and inferior trapezius [10] muscles.

Nodehi (2010) compared patients with and without impingement syndrome in terms of the isometric strength of the shoulder girdle muscles and reported that patients with retinal detachment syndrome had less strength in their shoulder muscles. Muscular strength was lower on the affected side of the patient. In patients with impingement syndrome, the ratio of the strength of lateral to medial rotating muscles was significantly lower than the control group [33]. Hannah, however, studied 13 female players and stated that there is no difference in the isometric strength of people with and without specular dyskinesis [20].

We studied only the isometric strength and endurance strength of the shoulder girdle muscles with hand dynamometer and pull-up bar in players with impingement syndrome. It is recommended that the concentric and eccentric strength of these muscles be studied with more precise and advanced devices.

\section{Conclusion}

In summary, the results of this study showed that in people with impingement syndrome, the kyphosis angle increased, the distance of the scapula from the spine at the affected side increased, the range of shoulder extension decreased, and the isometric strength of the shoulder involved in the abduction, flexion, and extension reduced.

These alterations disrupt the normal movement of the scapula and consequently may lead to impingement syndrome and impaired performance of the player. Based on the results, the rhythm of the scapulohumeral movement should be considered in the training and rehabilitation program of this group of players. Also, the scapula-supporting muscles (e.g. serratus anterior, rhomboids, and middle and lower trapezius) should be strengthened. To reduce dorsal kyphosis, the erector spine muscles should be strengthened and pectorals major, rhomboids, and trapezius stretched. Furthermore, abductor muscles, including the middle deltoid and supraspinatus are recommended to be strengthened.

\section{Ethical Considerations}

\section{Compliance with ethical guidelines}

All ethical principles were observed and all participants signed the written consent form.

\section{Funding}

The present paper was extracted from the MSc. thesis of the second author, Department of Physical Education \& Sport Sciences, Faculty of Humanities, East Tehran Branch, Islamic Azad University.

\section{Authors' contributions}

All authors contribute in preparing this article.

\section{Conflict of interest}

The authors declared no conflict of interest.

\section{References}

[1] Cools AM, Johansson FR, Borms D, Maenhout A. Prevention of shoulder injuries in overhead athletes: A science-based approach. Brazilian Journal of Physical Therapy. 2015; 19(5):3319. [DOI:10.1590/bjpt-rbf.2014.0109] [PMID] [PMCID]

[2] Kim SG. Correlation between scapular asymmetry and differences in left and right side activity of muscles adjacent to the scapula. Osong Public Health and Research Perspectives. 2017; 8(4):255-9. [DOI:10.24171/j.phrp.2017.8.4.04] [PMID] [PMCID]

[3] Ramsi M, Swanik KA, Straub S, Mattacola CG. Shoulderrotator strength of high school swimmers over the course of a competitive season. Journal of Sport Rehabilitation. 2004; 13(1):9-18. [DOI:10.1123/jsr.13.1.9]

[4] Lynch SS, Thigpen CA, Mihalik JP, Prentice WE, Padua D. The effects of an exercise intervention on forward head and rounded shoulder postures in elite swimmers. British Journal of Sports Medicine. 2010; 44(5):376-81. [DOI:10.1136/ bjsm.2009.066837] [PMID] 
[5] Kibler WB. Scapular involvement in impingement: Signs and symptoms. Instructional Course Lectures. 2006; 55:35-43. [PMID]

[6] Khanmohammadi R, Talebian S, Shadmehr A, Entezari E. [Electromyographic analysis of shoulder impingement syndrome versus normal subjects (Persian)]. Modern Rehabilitation. 2011; 5(2):9-16. http:/ / mrj.tums.ac.ir/article-1-70-en.html

[7] Keshavarz R, Bashardoust S, Mir SM, Ashrafi H. [Investigation of results of scapular assistant test in patients with shoulder impingement syndrome and rotator cuff tear: A clinical pilot study (Persian)]. Journal of Paramedical Sciences \& Rehabilitation. 2017; 6(1):26-38. http://jpsr.mums. ac.ir/article_8308_en.html

[8] Bennett ME, Boggs IJW, Chae J. Systems and methods for treating shoulder pain related to subacromial impingement syndrome [Internet]. 2019 [Updated 2019 Jan 1]. Available from: https:// patents.google.com/patent/US10166384B2/en

[9] Bergfeld JA. Sports injuries: Mechanisms, prevention, treatment. Journal of Bone \& Joint Surgery. 2002; 84(7):1294-5. [DOI:10.2106/00004623-200207000-00042]

[10] Nodehi Moghadam A, Vahabi SP, Norasteh AA, Abolhasani $\mathrm{H}$. [Comparing isometric strengths of shoulder girdle muscles in females with and without scapular dyskinesis (Persian)]. Archives of Rehabilitation. 2018; 19(2):92-101. [DOI:10.32598/rj.19.2.92]

[11] Vaughn DW, Brown EW. The influence of an in-home based therapeutic exercise program on thoracic kyphosis angles. Journal of Back and Musculoskeletal Rehabilitation. 2007; 20(4):155-65. [DOI:10.3233/BMR-2007-20404]

[12] Houglum PA. Therapeutic exercise for muskuloskeletal injuries. Champaign: Human Kinetice; 2005. https:/ / books. google.com/books?id=snfZl1KxHA0C\&dq

[13] Kibler WB, Thomas SJ, Sciascia AD. The role of the scapula in the overhead athlete. In: Kibler WB, Sciascia AD, editors. Mechanics, pathomechanics and injury in the overhead athlete: A case-based approach. Cham: Springer; 2019. pp. 15164. [DOI:10.1007/978-3-030-12775-6_11]

[14] Wang HK, Cochrane T. Mobility impairment, muscle imbalance, muscle weakness, scapular asymmetry and shoulder injury in elite volleyball athletes. The Journal of Sports Medicine and Physical Fitness. 2001; 41(3):403-10. https:/ / europepmc.org/article/med/11533574

[15] Smith J, Kotajarvi BR, Padgett DJ, Eischen JJ. Effect of scapular protraction and retraction on isometric shoulder elevation strength. Archives of Physical Medicine and Rehabilitation. 2002; 83(3):367-70. [DOI:10.1053/apmr.2002.29666] [PMID]

[16] Tripp BL, Yochem EM, Uhl TL. Recovery of upper extremity sensorimotor system acuity in baseball athletes after a throwing-fatigue protocol. Journal of Athletic Training. 2007; 42(4):452-7. [PMID] [PMCID]

[17] Seyedjafari E, Sahebozamani M, Daneshjoo A. [The effect of functional fatigue program on shoulders' proprioception among active swimmers (Persian)]. Journal for Research in Sport Rehabilitation. 2016; 3(6):31-7. https:/ / www.magiran. com/paper/1548925?lang=en

[18] Alizadehkhaiyat O, Roebuck MM, Makki AT, Frostick SP. Postural alterations in patients with subacromial impingement syndrome. International Journal of Sports Physical
Therapy. 2017; 12(7):1111-20. [DOI:10.26603/ijspt20171111] [PMID] [PMCID]

[19] Mackenzie TA. Factors influencing the Acromio-Humeral distance in elite athletes [PhD dissertation]. Salford University of Salford; 2016. https:// bit.ly/2CMsLhj

[20] Hannah DC, Scibek JS, Carcia CR. Strength profiles in healthy individuals with and without scapular dyskinesis. International Journal of Sports Physical Therapy. 2017; 12(3):305-13. [PMID] [PMCID]

[21] Uhl TL, Kibler WB, Gecewich B, Tripp BL. Evaluation of clinical assessment methods for scapular dyskinesis. Arthroscopy. 2009; 25(11):1240-8. [DOI:10.1016/j.arthro.2009.06.007] [PMID]

[22] Hosseinimehr SH, Anbarian M, Khosravi MT. [The survey of scapulohumeral rhythm and isometric strength ratio of shoulder agonist to antagonist muscles in handball players and non-athletes (Persian)]. Journal of Sport Medicine Review. 2014; 5(14):15-30. https://www.magiran.com/ paper/1239277?lang=en

[23] Heidari S, Shamsi Majlan A, Daneshmandi H, Khoshraftar Yazdi N. [Strength ratio between agonist and antagonist muscles and range of motion of the shoulder in female volleyball players and non athletes (Persian)]. Research in Sport Medicine and Technology. 2017; 15(14):23-35. http://jsmt. khu.ac.ir/article-1-233-en.htm

[24] Daneshmandi H, Rahmaninia F, Esmaili S. [Comparative study of rom's shoulder in atheletes and it's relationship to history playing and post (Persian)]. Olympic. 2005; 13(1):29-39. https:/ / www.sid.ir/Fa/Journal/ViewPaper.aspx?ID=20034

[25] Gray JC, Grimsby O. Interrelationship of the spine, rib cage, and shoulder. In: Donatelli RA, editor. Physical therapy of the shoulder. Berlin: Elsevier; 2012. p. 87-130. [DOI:10.1016/ B978-1-4377-0740-3.00005-2]

[26] Briggs AM, Wrigley TV, Tully EA, Adams PE, Greig AM, Bennell KL. Radiographic measures of thoracic kyphosis in osteoporosis: Cobb and vertebral centroid angles. Skeletal Radiology. 2007; 36(8):761-7. [DOI:10.1007/s00256-007-0284-8] [PMID]

[27] Lewis JS, Green A, Wright C. Subacromial impingement syndrome: The role of posture and muscle imbalance. Journal of Shoulder and Elbow Surgery. 2005; 14(4):385-92. [DOI:10.1016/j.jse.2004.08.007] [PMID]

[28] Kibler WB, Sciascia AD. Mechanics pathomechanics and injury in the overhead athlete: A case-based approach to evaluation, diagnosis and management. Berelin: Springer; 2019. [DOI:10.1007/978-3-030-12775-6]

[29] Merolla G, De Santis E, Campi F, Paladini P, Porcellini G. Supraspinatus and infraspinatus weakness in overhead athletes with scapular dyskinesis: Strength assessment before and after restoration of scapular musculature balance. Musculoskeletal Surgery. 2010; 94(3):119-25. [DOI:10.1007/ s12306-010-0082-7] [PMID]

[30] Rajabi H, Alizadeh MH, Bayat MR. [The relationship between the position of the scapular and shoulder girdle muscles endurance (Persian)]. Journal of Harkat. 2004; 20:73-85. http://ensani.ir/fa/article/download/186378

[31] Lopes AD, Timmons MK, Grover M, Ciconelli RM, Michener LA. Visual scapular dyskinesis: Kinematics and muscle activity alterations in patients with subacromial 
impingement syndrome. Archives of Physical Medicine and Rehabilitation. 2015; 96(2):298-306. [DOI:10.1016/j. apmr.2014.09.029] [PMID]

[32] Harrison AK, Flatow EL. Subacromial impingement syndrome. Journal of the American Academy of Orthopaedic Surgeons. 2011; 19(11):701-8. [DOI:10.5435/00124635201111000-00006] [PMID]

[33] Nodehi Moghadam A, Rouhbakhsh Z, Ebrahimi E, Salavati $M$, Jafari $D$. [A comparative study on isometric muscles strength of shoulder complex between persons with and without impingement syndrome (Persian)]. Journal of Gorgan University of Medical Sciences. 2010; 12(2):26-32. http://goums.ac.ir/journal/article-1-729-en.html 
This Page Intentionally Left Blank 